\title{
Sentidos del trabajo religioso en contextos marcados por la violencia: estudio en un complejo de favelas en Río de Janeiro
}

\author{
Meanings of religious work in contexts marked by \\ violence: a study in a complex of shantytowns in Rio de \\ Janeiro
}

Fernanda Mendes Lages Ribeiro', Maria Cecília de Souza Minayo²

${ }^{1}$ Doctora en Salud Pública. Investigadora colaboradora Departamento de Estudios de Violencia e Salud Jorge Careli, Escola Nacional de Salud Pública, Fundação Oswaldo Cruz, Rio de Janeiro, Brasil. $\triangle$ (iD)

${ }^{2}$ Doctora en Salud Pública. Investigadora titular, Departamento de Estudios de Violencia e Salud Jorge Careli Escola Nacional de Salud Pública, Fundação Oswaldo Cruz, Rio de Janeiro, Brasil. $\square$ (iD)
RESUMEN Este trabajo se propone comprender los sentidos del trabajo religioso en la prevención de la violencia y la recuperación de personas involucradas con actos ilícitos en un complejo de favelas de la ciudad de Río de Janeiro, Brasil. Se analizan la acción de entidades religiosas en el territorio, las visiones de sus líderes sobre su papel y el de su iglesia y sus representaciones sobre el territorio y sobre las personas que realizan actos violentos. Entre 2010 y 2012, desde un abordaje cualitativo, se realizó observación participante y se efectuaron entrevistas a líderes religiosos y "convertidos", cuyos relatos se abordaron a través de análisis de la enunciación. Los líderes resaltan la importancia de la acción de sus iglesias en una localidad precaria y violenta y los "convertidos" destacan el papel de la evangelización en su conversión religiosa. Sin embargo, las relaciones entre religión y violencia son complejas e incluyen varios tipos de trayectorias y comportamientos: si bien se destaca la fuerza del apoyo religioso, también se la cuestiona. Se concluye que las iglesias actúan de forma puntual e individual, por lo que colaboran poco con la transformación de la realidad, asumiendo con frecuencia un papel de control y de pacificación de la cuestión social.

PALABRAS CLAVES Religión; Violencia; Organizaciones Religiosas; Poblaciones Vulnerables; Control Social; Brasil.

ABSTRACT The purpose of this study is to understand the meanings of religious work
in the prevention of violence and in the recovery of people involved in illicit acts in a
complex of shantytowns in Rio de Janeiro, Brazil. The activities of religious entities in
the territory, the view of religious leaders regarding their role and that of their church,
and the representations of the territory and of the people who commit violent acts
were analyzed. Using a qualitative approach, participant observation and interviews of
religious leaders and "converts" were conducted between 2010 and 2012 . The resulting
narratives were treated using enunciation analysis. The leaders emphasize the importance
of their churches' actions in violent and precarious areas, while the "converts" highlight
the role of evangelization in their religious conversion. However, the relationships
between religion and violence are complex, involving various types of trajectories and
behaviors; in this way, the strength of religious support in the conversion process is
both highlighted and questioned. The text concludes that churches' actions tend to be
palliative and focused on the individual and therefore do little to transform reality, with
the church potentially taking on roles of social control and pacification. KEY WORDS Religion; Violence; Faith-Based Organizations; Vulnerable Populations; Social Control; Brazil. 


\section{INTRODUCCIÓN}

Prevención y recuperación son términos nativos del sector salud. Problematizar la religión como prevención significa, en este trabajo, analizarla como un factor que puede evitar que las personas se involucren en situaciones de violencia y, como recuperación, en el sentido de cesar ese vínculo una vez que se produjo.

Principalmente, a partir de las décadas de 1970 y 1980, diversos trabajos han discutido el significado del apoyo de diversas corrientes religiosas en temas como recuperación de enfermedades, uso de drogas, calidad de vida, entre otros ${ }^{(3,4,5,6,7,8,9,10,11,12,13)}$. Para muchos autores, la religión puede ser una ayuda del tratamiento convencional o puede incluso sustituirlo en casos de ausencia de servicios de salud o de no creencia en su efectividad ${ }^{(8,12,14,15)}$. Algunos trabajos investigan, particularmente, la relación entre salud mental y religión, tanto en el sentido de protección como en el de apoyo a los procesos de recuperación y de rehabilitación ${ }^{(7,12,13,16)}$.

La mayoría de los estudios muestra que la religión es una de las dimensiones relevantes en la definición de cómo la persona se comporta en el mundo y busca dar sentido a su existencia. Algunos señalan que las personas religiosas son más altruistas y solidarias con aquellos que sufren y tienen actitudes de aproximación y de contención ${ }^{(17,18)}$. Esa visión, sin embargo, no es unánime. Otros, destacan que la religión también puede producir sufrimiento psíquico y violencia, en la medida en que las creencias discriminan a ciertos grupos, los excluyen y rotulan ${ }^{(19,20)}$

Sobre todo, en la antropología y en la sociología, un considerable número de autores ha abordado la relación entre violencia, prevención, recuperación y rehabilitación, en particular, en estudios sobre personas en prisión. En Brasil, existen investigaciones sobre el papel que han tenido las instituciones religiosas en las favelas, ofreciendo diversas acciones, entre ellas, apoyar a personas en situación de vulnerabilidad y enfrentar situaciones de vida particularmente desafiantes, en la formación de comunidades de fe $\mathrm{e}^{(12,13,14,2}$ $1,22,23,24,25,26,27,28,29,30)$. A su vez, diversos autores han mapeado movimientos de algunos grupos, sobre todo pentecostales y neopentecostales, de oposición violenta a las religiones de matriz africana. Tal oposición incluye la destrucción de espacios, el ataque a líderes y la difusión de noticias discriminatorias en los medios de comunicación nacional, contra territorios marginalizados de las ciudades y grupos sociales como la población LGBT, entre otros ${ }^{(6,30,31,32,33,34,35)}$, atrayendo más adeptos. La adhesión a la fe también puede ofrecer fuerzas para abandonar aquello que es considerado pecado en la concepción religiosa de algunas creencias: abuso de alcohol y otras drogas, adulterio, homosexualidad, vínculo con la criminalidad, entre otros.

Para Valla ${ }^{(8)}$ la religión puede ser "una forma particular y espontánea de expresar los caminos que las clases populares eligen para enfrentar sus dificultades en el cotidiano". En este sentido, la fe y el apoyo religioso suelen formar parte de las estrategias de supervivencia de los habitantes en territorios donde diversos derechos son negados, lo que significa para muchos, una forma de salvación, en la medida en que consideran encontrar liberación, cura y fuerza para el cambio de conducta. Las redes sociales formadas por las iglesias han servido como espacio de contención y protección ante un cotidiano de vulnerabilidades y violencias.

Según Minayo, el campo religioso forma parte de la cultura popular, así como las explicaciones sobre la relación salud/enfermedad. Su característica principal es "la relación intrínseca entre la fe y la gracia. [...] Ella acerca el milagro y lo integra al cotidiano, como solución, a veces única, para los sufrimientos del día a día" (31).

En especial, a partir de las dos últimas décadas se ha registrado la expansión de las iglesias evangélicas, particularmente, en las áreas más empobrecidas de Brasil, como consta en los dos últimos censos demográficos del Instituto Brasileño de Geografía y Estadística 2000 y 2010. Sin embargo, históricamente, no son las únicas que ocupan el espacio y desarrollan acciones sociales, 
como las denominadas de "salvación". La iglesia católica siempre marcó presencia en las localidades más pobres del país. Especialmente, a partir de los años 1960, se colocó a la par de los vecinos en la reivindicación de sus derechos y para que las favelas fuesen reconocidas como territorios legítimos de la ciudad.

Por tanto, la participación de las organizaciones religiosas en la esfera pública, social y política en Brasil es histórica. En los últimos años, sin embargo, se destaca una ostensible presencia de los evangélicos en los partidos políticos, en las diversas esferas gubernamentales y en acciones sociales en las que participan como organizaciones no gubernamentales (ONG), buscando influir en la sociedad de forma conservadora. Desde el punto de vista político, es notoria, por ejemplo, su militancia en proyectos para prohibir cualquier tipo de aborto y la legalización de la unión estable entre personas del mismo sexo. Según Bohn ${ }^{(36)}$ la Ilamada "bancada evangélica" en Brasil, conforma en la actualidad una especie de "nueva derecha" que defiende banderas conservadoras y se autoproclama guardiana de la moralidad familiar y social en nombre de Dios. En la esfera social, las ONG religiosas capturan recursos de las tres esferas de gobierno para acciones asistenciales, en un proceso de tercerización de los servicios públicos.

Este trabajo se propone discutir algunas relaciones entre religión, prevención de la violencia y recuperación de personas, sobre la base de la investigación "Visões e Estratégias sobre a religião en la promoção, prevenção e recuperação de pessoas implicadas com a violência". El estudio fue realizado en un complejo de favelas de la ciudad de Río de Janeiro, Brasil, e incluyó líderes religiosos e individuos que abandonaron el crimen a través de la conversión religiosa, quienes serán denominados aquí como convertidos. Se los invitó a narrar sus percepciones acerca del tema, a partir de sus trayectorias de vida en el territorio.

Los términos religión y violencia fueron centrales en el trabajo de campo y en la búsqueda de bibliografía científica. Otros trabajos derivados de esta investigación ya han sido publicados ${ }^{(1,2)}$.

\section{Contextualización}

Las favelas cariocas -marcadas por grandes desigualdades sociales, económicas y culturales y por grandes desafíos para garantizar los derechos y el acceso a las políticas- han sido centro, históricamente, de una serie de intervenciones y de políticas sociales por parte del Estado. La opinión pública suele representarlas como "territorios de carencias" ${ }^{\prime(37)}$. Según Perlman ${ }^{(38)}$, en su clásica obra sobre los principales estereotipos construidos por los gobiernos, los teóricos y el sentido común respecto de los habitantes de las favelas, menciona que el mito de la marginalidad construye un imaginario sobre los pobres y el lugar en el que viven como "aglomerados patológicos", "comunidades en busca de superación" o como "calamidad inevitable". Las favelas aparecen también como un problema de seguridad en las ciudades, lo que justifica la creación e implementación de políticas específicamente direccionadas a ellas, que termina criminalizándolas aún más. La "ciudad partida", según Silva, se construye en función de esos estigmas, pues hay un "confinamiento geográfico y simbólico que deriva en una concepción de mundos aparte" (39).

El locus de este estudio es un complejo de 16 favelas situado en la zona norte de la ciudad de Río de Janeiro, Brasil. Su población estimada es de 50.000 personas, según el blog Participação Cidadã na Gestão da Saúde ${ }^{(40)}$. Entre las principales deficiencias relacionadas con la salud de la población, de acuerdo con la misma fuente, están: vulnerabilidad al dengue y la tuberculosis; altos índices de traumatismos asociados a la violencia y a las condiciones sociales en general; abuso de alcohol y otras drogas; violencia doméstica, sexual y reproductiva; agravios a la salud en el trabajo; hipertensión y diabetes; y déficit nutricional. Además, son relevantes las tasas de embarazo precoz, de mortalidad juvenil, de abandono infantil, de abandono escolar y de trabajo infantil. 
Al igual que otras favelas cariocas, este complejo "está marcado por la precaria condición urbana"(41). Por un lado, una parte considerable de su población está aún excluida de los derechos sociales básicos y su territorio está atravesado por diversas desigualdades sociales, con altos índices de violencia, que afectan principalmente a hombres jóvenes. Por otro lado, existen iniciativas locales muchas veces invisibles, así como una gran variedad de acciones intersectoriales y de programas sociales gerenciados por el poder público y por organizaciones de la sociedad civil.

Desde el año 2008, el complejo pasó por diversos proyectos financiados por políticas públicas a partir de un plan del Gobierno Federal en conjunto con el Gobierno del Estado, que apuntaba a mejorar las condiciones del lugar. Se constituyeron equipos sociales, de salud, de esparcimiento, enseñanza y ciudadanía, se entregaron unidades habitacionales y se realizaron intervenciones urbanísticas en una de las vías principales que atraviesan el territorio, con el propósito de evitar inundaciones. Se elevaron las vías del ferrocarril para crear un espacio de esparcimiento y erradicar la gran cracolandia (término que denomina el espacio de venta y consumo de drogas y permanencia de usuarios, en especial del crack). Al respecto, Bodstein ${ }^{(41)}$ señala que "el plan traduce la percepción de que la superación de la criminalidad y la violencia no puede darse exclusivamente desde la óptica de la seguridad pública, sin mejorar las condiciones de vida". Sin embargo, existen diversos problemas con relación al desarrollo de este plan, que cuenta con obras en las calles y en las casas, saneamiento básico, red eléctrica, movilidad, espacios verdes y la relación entre los habitantes y el poder público ${ }^{(42)}$.

Existen, además, obstáculos para que el poder público reconozca, apoye e integre iniciativas, movimientos y acciones colectivas locales. Entre las muchas iniciativas tanto de la población como para la población, se consideran en este estudio las promovidas por instituciones religiosas. En el lugar hay una serie de estas entidades que promueven acciones con potencial impacto de alcanzar, efectivamente, a la población. El soporte está dado por medio de la provisión de servicios -acciones de caridad, alfabetización, cursos, deporte y esparcimiento, asistencia jurídica, grupos de apoyo a mujeres y jóvenes, cuidados vinculados a la prevención del abuso del alcohol y otras drogas, además de actividades específicamente religiosas- y de la elaboración de un sentido de comunidad que, entre otras funciones, promueve la contención y el apoyo, como lo señalan diversos autores ya citados. Se busca analizar críticamente cómo operan tales instituciones y qué funciones cumplen en el territorio.

\section{MATERIAL Y MÉTODO}

Los datos provienen de entrevistas y de observación participante realizadas entre 2010 y 2012 en el marco de una investigación cualitativa. Para llegar a las iglesias y asociaciones religiosas se utilizó un relevamiento de instituciones del complejo de favelas y se realizaron contactos con diversos interlocutores claves que actúan, viven y prestan servicios en la localidad.

Luego de contactar telefónicamente a un total de 33 instituciones de carácter religioso localizadas por entonces en el territorio, el estudio incluyó 14: siete iglesias evangélicas, cuatro católicas y tres asociaciones espiritistas. Entre las evangélicas, se incluyen unidades de la Asamblea de Dios, Iglesia Universal del Reino de Dios, Iglesia Batista e Iglesia Presbiteriana. Se visitaron las instituciones que aceptaron participar y se las estimuló a cooperar con el estudio, buscando garantizar la pluralidad de la representación de los segmentos religiosos. El tiempo transcurrido desde que estas entidades se asentaron en el lugar varía entre 15 y 70 años, lo que muestra su inserción en la realidad social. Se constató que todos los líderes religiosos cuentan con varios años de trabajo en el territorio y algunos de ellos -los de las iglesias evangélicas, principalmente- también son residentes, lo que los hace mucho más cercanos a los habitantes. Varios de ellos están involucrados en 
acciones de participación social en conjunto con otras organizaciones locales públicas y privadas. Cabe destacar que no se encontró ninguna entidad o grupo vinculado a religiones de matriz africana, incluso luego de realizar una búsqueda activa junto a los participantes e informantes claves. Esa ausencia puede ser indicio del proceso de persecución y expulsión de los religiosos y destrucción de sus locales de expresión cultural por parte de grupos fundamentalistas evangélicos, en varios barrios de Río de Janeiro.

Se realizaron entrevistas individuales a cinco líderes religiosos: dos de iglesias evangélicas (Asamblea de Dios e Iglesia Batista) y tres católicos. También, por indicación de los líderes, se entrevistaron a tres individuos identificados como convertidos a religiones evangélicas, quienes habían participado en actos ilícitos antes de la conversión. Dos pertenecían a unidades de la Asamblea de Dios, uno de ellos era pastor. El tercero, que también se hizo pastor, dirigía una ONG cuya misión es recuperar, resocializar, calificar y reintegrar "ex presos" y "drogadictos", insertándolos en centros de tratamiento a partir de convenios con una serie de iglesias pentecostales.

Por motivos éticos, para preservar el anonimato, se omite identificar las instituciones. Todos los entrevistados están identificados a través de sus iniciales o por el nombre de la iglesia a la cual pertenecen (los números diferencian a quienes pertenecen a una misma iglesia).

El pequeño número de participantes se justifica por el método de estudio de caso, en el cual la investigación analiza la complejidad de los objetos sociales específicos, particulares, para lo cual se utilizan "estrategias de investigación cualitativa para mapear, describir y analizar el contexto, las relaciones y las percepciones respecto de la situación"(43). Como uno de los objetivos era comprender el impacto del trabajo religioso desarrollado por diferentes entidades en la realidad concreta del territorio estudiado, se invitó a participar a las entidades existentes, y se incluyeron aquellas que aceptaron. Por lo tanto, el tipo de muestra utilizada fue intencional y relevante para el contexto social específico.

La actividad de observación participante incluyó frecuentar diversos lugares del complejo, visitar las iglesias, asistir a encuentros comunitarios, cultos y misas, y acompañar el trabajo social como, por ejemplo, las acciones de los religiosos en cracolandia. Todas las actividades de observación se registraron en diarios de campo. Además, forma parte del material de investigación la información proveniente de páginas web, periódicos y folders institucionales.

Una vez transcriptos los relatos se aplicó análisis de la enunciación, que "se apoya en una concepción de comunicación como proceso (y no como un dato estático) y del discurso como palabra en acto"(43). El discurso está conformado por aspectos históricos y sociales, por lo que las narrativas, al no ser algo acabado, solo pueden ser entendidas en la interacción del todo con las partes. Por eso, ningún relato fue considerado como desconectado del contexto ni de la situación del individuo que lo produjo. Forma parte de este tipo de análisis la contextualización de las condiciones de producción de la palabra y del análisis del discurso a partir de sus estructuras gramaticales, de la lógica que lo organiza, de sus silencios y lagunas y de las figuras de retórica empleadas por los interlocutores. Este tipo de análisis se justifica en los estudios de caso, dado que en la formación del corpus la "calidad del análisis sustituye la cantidad de material"(43) y el foco es la comprensión de los discursos, con sus idiosincrasias y sus significados, abordando cada entrevista como una unidad de análisis.

El estudio fue aprobado por el Comité de Ética de la Escola Nacional de Saúde Pública (Fiocruz-Brasil) bajo el código CAAE 0197.0.031.000-11 y cumplió con las normas para investigaciones con seres humanos, incluyendo la firma por parte de los participantes del consentimiento libre e informado. 


\section{RESULTADOS Y DISCUSIÓN}

\section{Representaciones sociales sobre el territorio: violencia, pobreza y precariedad de la presencia del Estado}

El complejo de favelas es representado por los líderes religiosos como un lugar muy pobre, donde es necesario promover acciones básicas: "vivimos hoy en una comunidad extremadamente miserable en todos los sentidos, espiritual, social, la cuestión de la salud aquí es muy precaria" (líder iglesia Batista). Tal representación fue unánime entre los líderes de diferentes denominaciones.

Estos sujetos describen el lugar como violento, en función de la presencia de grupos armados que dominan el territorio ${ }^{(44)}$ y de acciones represivas por parte del Estado. Ambos provocan conflictos que exponen la población a riesgos. Tales grupos marcan su presencia en el territorio a partir de acciones violentas, controlan la venta de drogas, usan armas de forma ostensiva y realizan otras actividades ilícitas. Como señalan Silva, Fernandes y Braga, ellos se benefician justamente de la precariedad de espacios estigmatizados y vulnerabilizados de la ciudad y de algunas características que marcan esas localidades, como la "baja participación del Estado como regulador y garante de derechos" ${ }^{\prime(44)}$.

En el relato de algunos religiosos, el abandono y la indiferencia del Estado están relacionados a las causas de la violencia. Según un líder católico, la iglesia termina actuando de forma compensatoria, dado que ofrece "un alivio, un consuelo, una cierta terapia para el alma y el espíritu" (líder iglesia católica 1). Ese mismo interlocutor denomina como "pecado social" el resultado de la estructura socioeconómica que mantiene ciertos lugares de la ciudad al margen, naturalizando la pobreza como producción social. Este tipo de discurso crítico y contextualizado emerge entre los líderes religiosos con mayor compromiso político, como es el caso de este participante.

El líder de la Asamblea de Dios también contextualizó el crimen como un "pecado", no atribuido exclusivamente al individuo, sino fruto de una producción social, económica y política. Los entrevistados entienden que ese "pecado" está construido en la dialéctica entre el ser y las diversas conexiones que lo construyen. De este modo, algunos líderes católicos y protestantes asocian la criminalidad a la falta de oportunidades de trabajo con salarios dignos, por un lado, y a la seducción del tráfico de drogas, por otro. Esa seducción aparece en sus discursos como muy poderosa, porque ofrece retorno financiero y estatus a personas que ocupan un lugar marginal ${ }^{45}, \mathrm{y}$ que difícilmente alcanzarían una posición mejor por medios regulares y legales.

No podemos decir y no creemos que las personas nazcan ya con eso [el hecho de ser criminal] predeterminado. En realidad, sabemos que es fruto de la sociedad, de valores o antivalores que fueron impuestos, como, por ejemplo, la ganancia fácil, manda aquel que tiene poder, aquel que tiene dinero. (Líder Iglesia Católica 2)

\begin{abstract}
Anteriormente, creía que el hombre no era fruto del ambiente en que vivía. Pero hoy creo que el ambiente tiene mucha influencia. Porque si vivimos en un ambiente miserable, como es ese complejo, vemos que las personas tienden a involucrarse. Son personas que no tuvieron condiciones de estudiar, no tienen condiciones de verlo. Ellas buscan un medio de vida más fácil y se van involucrando con la violencia. (Líder Asamblea de Dios)
\end{abstract}

Los márgenes -espacios Ilamados "sin ley", que reciben personas "no suficientemente socializadas" - se constituyen en formas del ejercicio del poder que están más allá de la acción del Estado ${ }^{(45)}$. Para atender a la necesidad constante de control de las amenazas, reales o potenciales, provenientes de los márgenes, diversos actores que tienen espacio en el territorio desarrollan estrategias basadas en la fuerza o en la pedagogía de la conversión.

Del discurso religioso de dos participantes se desprende que su papel de liderazgo los compele a hacer un análisis de los diferentes 
factores que impactan negativamente en la vida de las personas de sus comunidades de fe, como punto central de su acción evangelizadora. Concluyen que el complejo de favelas donde cumplen su misión funciona como una especie de ecosistema que produce y alimenta la criminalidad. Los elementos de ese ecosistema son: precaria presencia del Estado, abandono político, pobreza, violencia por parte de grupos criminales armados y enfrentamiento con fuerzas policiales. Al abordar los sistemas complejos, Minayo y Constantino destacan que hay una articulación entre el ambiente externo, el sistema social y la subjetividad que influye "tanto en la construcción de la solidaridad, como en la responsabilidad por la desintegración social"(46).

Más que pertenecer a una u otra denominación, la presencia en el territorio en el que se localizan las iglesias, les da a los líderes una percepción más cercana de los aspectos de la criminalidad con la cual conviven. Sin embargo, su visión pesimista y las representaciones sociales negativas sobre los habitantes y su entorno comprometen la comprensión de los aspectos positivos de la riqueza de la vida y del trabajo que se realiza allí, y permiten la reproducción de estereotipos que dificultan la transformación social. Los estereotipos negativos también impregnan los discursos políticos, las acciones gubernamentales y las acciones de muchas ONG, reforzando el mito de las clases peligrosas y la criminalización de los habitantes de la favela $^{(39)}$. El ecosistema considerado violento, según algunos líderes, también plantea desafíos para el accionar de las iglesias:

Ser pastor allá afuera es muy fácil, la gente es educada, ya está pulido. Pero aquí dentro no, son personas llenas de neurosis, personas que son producto del estupro, que viven en casas donde la madre es adicta, que es golpeada casi todos los días, son personas traumatizadas. (Líder Asamblea de Dios)

Este relato expresa una fuerte representación social respecto del territorio violento y sus efectos nocivos e ineludibles sobre los habitantes. Vivir en un ambiente Ilamado "criminal" de la ciudad partida ${ }^{(39)}$ crearía individuos problemáticos que desafiarían la propia fuerza de acción de los religiosos. Tal visión -y su explicitación a través del discurso religioso- posee un efecto recursivo en la reproducción de estigmas, pues reifica la visión del sentido común sobre el lugar. De existir una crítica de ciertos líderes acerca del "pecado social", esta no acompaña la reflexión sobre las implicancias de un discurso que reafirma la peligrosidad del ecosistema. Al contrario, refuerza los aspectos negativos del espacio y, al mismo tiempo, enfatiza la importancia de la actuación religiosa como una de las únicas opciones de salvación.

\section{La conversión religiosa a través de la evangelización: trayectorias modulares}

El trabajo social y el religioso son indisociables en la visión de los líderes de ambas denominaciones. Misas, evangelización y cursos con contenido religioso son estrategias de prevención para no involucrarse en actos de violencia y de recuperación de personas ya involucradas. Sin embargo, la conversión religiosa -como experiencia de ruptura con una vida anterior e inicio de una nueva vidaes construida dentro de la idea de salvación por los participantes de las denominaciones protestantes.

A través de la predicación del Evangelio esas personas han encontrado confort para su alma, para salir de algunas situaciones en las que vivían, como personas del tráfico, personas que vivían en la prostitución, que eran dependientes químicos. El agente que promueve más transformaciones de los que conozco, en realidad, son las iglesias, porque la mayoría de las personas que frecuentan la iglesia, son personas "ex alguna cosa". Pero gracias a Dios, la gente ha tenido éxito, trabajando, hablando de Jesús para las personas que ya eran del tráfico aquí dentro y hoy están recuperadas. (Miembro de la Asamblea de Dios) 
La dependencia de las drogas $y$, específicamente, del crack, es una cuestión que moviliza tanto a los líderes como a los convertidos. Diversas narrativas señalan la comprensión de sus efectos en la vida de los usuarios en una trayectoria que se extiende del uso a la dependencia y a los actos ilícitos para sustentar el uso, lo cual impacta en el territorio. La principal acción emprendida por los líderes, registrada tanto entre evangélicos como entre católicos, es la evangelización en las bocas de fumo (lugares de venta de drogas) y en las cracolandias, uniendo la contención a través de la palabra con la provisión de algunos alimentos y el ofrecimiento de ayuda para el tratamiento. Esa acción está marcada por la asociación con casas de recuperación (las Ilamadas comunidades terapéuticas), a través del tratamiento religioso. Casi todos los líderes afirmaron que sus instituciones patrocinan vacantes en estos establecimientos. Actualmente, se le ha otorgado un peso significativo a la problemática de las drogas, en especial, el crack, chivo expiatorio de todos los males sociales, incluso en las políticas nacionales de seguridad pública(2). Las construcciones discursivas de los sujetos de investigación acerca de este tema están fuertemente atravesadas por las ideas de peligrosidad, violencia en el territorio e importancia de la intervención religiosa.

Los participantes describen el espacio institucional de las iglesias -tanto físico como de la comunidad de fe-como base de apoyo. Según Guimarães, Valla y Lacerda ${ }^{(15)}$ las redes formadas por los miembros de la iglesia ofrecen protección ante un contexto de violencias y dificultades económico-sociales y un espacio de contención para aquello que no encuentra explicación ni solución en la medicina. Según estos autores, la fe y la pertenencia a un grupo de hermanos son potentes instrumentos de rescate de las personas involucradas con la violencia. Se concibe que la apertura de las iglesias a la circulación de personas puede configurar una forma de prevención de la participación en actos delictivos y de recuperación de los ya "desviados", lo cual puede representar, para algunos, una chance de percibir que otro tipo de vida es posible. La participación en actividades religiosas grupales tiene importancia cabal para reforzar la fe y la cohesión moral. En el proceso de conversión, hay un pasaje entre "aceptar a Jesús" y "aceptar el Evangelio", que significa formar parte de una iglesia y compartir una nueva red de sociabilidad y un nuevo ethos ${ }^{(47)}$. Según Rocha ${ }^{(13)}$, es la comunidad religiosa "quien provee la estructura de plausibilidad indispensable para conservar y mantener la nueva realidad subjetiva", actuando como un aparato legitimador.

Las relaciones establecidas entre vida criminal y el ejercicio de la fe religiosa son diversas. Los entrevistados relatan que la conversión no significa, necesaria o exclusivamente, adentrarse en un nuevo destino definitivo. Las personas consideradas convertidas, cuyos relatos formaron parte de esta investigación y eran practicantes de religiones protestantes, traducen tales relaciones en la distinción entre "practicar una religión" y "tener una creencia". A partir de su percepción, informada a través de su vivencia entre los mundos del crimen y de la fe, afirman que muchas personas utilizan la religión como refugio, o sea, como una especie de escondite. Según ellos, esto no es lo mismo que tener una práctica religiosa personal consistente. En ese caso, el juicio moral valoriza más la espiritualidad que los ritos, y la primera es percibida como más sincera. La religiosidad, afirman, no debe restringirse a una institución. Según el discurso de una persona convertida, que se autoidentifica como "pastor ex usuario de drogas y ex traficante", la "religión en realidad, no cambia la vida de la persona. La religión, para muchas personas, es un refugio. [...] Yo encontré la solución cuando tuve un encuentro con Jesús" (R).

En lo referente a las posibilidades de recuperación a través de la religión, la principal estrategia es la evangelización, cuya meta, para las iglesias evangélicas, es la conversión. Esta presupone, teóricamente, una transformación total, en la cual el sujeto pasa a adoptar un nuevo universo al identificarse con los principios de cierta denominación. Seguir su cosmología implica romper con modos de vida anteriores que no se ajustan 
a los nuevos presupuestos y al nuevo proyecto idealizado de hombre. A partir de las trayectorias de los participantes de esta investigación, se puede inferir qué significa dejar de involucrarse con la violencia asociada a actividades ilegales, como la venta y el uso de drogas y sus formas de protección. Así, "aquel que tiene el Evangelio dentro de su vida, que tiene el reino de Dios en su interior, no es violento, no cabe la violencia. La violencia está fuera de la vida de quien tiene a Jesús" (M).

Sin embargo, ambos, religiosos y convertidos, al atribuir significados a las relaciones entre religión y violencia en el contexto de la investigación que dio origen a este artículo, fueron unánimes en señalar la complejidad y la no linealidad del proceso de conversión. Los Ilamados convertidos reconstruyeron discursivamente sus historias de vida, su participación en tráfico de drogas, acciones violentas y abuso/dependencia de sustancias ilícitas, rememorando su impacto destructivo. Estas personas narraron los episodios de su vida tanto en las entrevistas formales como en las charlas informales, teniendo como telón de fondo la vivencia privilegiada en el territorio y el contacto cercano con los trabajos de evangelización: como evangelizador o como evangelizado, o con doble pertenencia.

Del discurso de los convertidos se desprende que la conversión implica un cambio de habitus ${ }^{(48)}$ cuyo sentido es transformador de las vivencias asociadas a la violencia. Este cambio es la principal categoría transversal en sus discursos, que expresa la rehabilitación, la adopción de una vida correcta, y la inserción en una comunidad de fe. Los entrevistados evocaron la imagen del "fondo del pozo" para hablar sobre un momento extremo de su vida, destacando que "el buscar a Dios se da en momentos de desesperación" (L). Uno de los participantes (R) narró que fue evangelizado a través de una emisora de radio, cuando sintió que el pastor le hablaba directamente a él, pues citaba todo lo que él había hecho y lo que sentía. Se sintió entonces incitado a ir a un culto de la iglesia que ya frecuentaba su esposa, donde de hecho se produjo su conversión. Este caso ejemplifica que una de las principales estrategias de evangelizar, la conversión, se completó exitosamente, dentro de la concepción de las religiones pentecostales.

Según otro participante $(M)$ su conversión se dio a partir de la inserción en una comunidad terapéutica donde se rehabilitó de la dependencia a las drogas a través de la oración: "iba, me arrodillada, oraba [...] leía la Biblia y pedía a Dios, y Dios fue trabajando en mi vida". En este caso, el proceso de cambio que culminó con la rehabilitación de la persona ocurrió concomitantemente y por intermedio de una transformación más amplia que "recuperó el individuo para Dios" a través del trabajo religioso.

El "fondo del pozo" representa la cima del proceso de decadencia de diversas trayectorias, y puede funcionar como disparador del cambio. En ese contexto, el testimonio tiene gran importancia como técnica de recuperación, y se materializa a partir de la palabra que transforma la historia de los sujetos, mide su grado de compromiso y ejerce control. En el cotidiano, "ser" el testimonio aporta pruebas de la autenticidad de la transformación ${ }^{(49)}$. Es por medio de ese testimonio que el fiel divulga las gracias, y se transmuta en evangelizador. Según Mafra ${ }^{(50)}$, el testimonio refuerza y "engrandece el efecto de la metamorfosis", cuya importancia pasa del individuo en sí al hecho.

A pesar de que los convertidos consideren que aquellos que se toman en serio la conversión no vuelven a involucrarse con el crimen, admiten que se producen recaídas. El mismo es mencionado por todos los líderes religiosos, católicos y evangélicos, al rememorar trayectorias de personas que conocieron. Destacan que las conversiones no se dan "de la noche a la mañana", pues suponen una cierta maduración (líder iglesia católica 3). "La fe es una propuesta. Ahora, cambiar o no es un proceso" (líder iglesia católica 1). Ese proceso varía de persona en persona, implica recaídas y la construcción de una nueva forma de estar y de relacionarse con el mundo. 
Empecé a sentirme con condiciones para superar la vida que vivía, aunque tuve algunas recaídas, porque es muy difícil [...]. ¿Pero qué hice? Resistí. [...] Y fue a través de Dios que mi vida cambió. Comencé a ir a la iglesia, ¿sabés? [...]. Y ahí, empecé a cambiar mucho. No fue de un día para otro, fue un proceso. Hoy hace veinticinco años que estoy en la iglesia. (R)

Este testimonio nos muestra que la adhesión a una religión puede culminar con la conversión, pero que son posibles también otros tipos de combinaciones que llevan a distintos comportamientos.

Están las personas que, aunque vayan a misa y a la iglesia, mantienen una vida, digamos, criminal, o que, de repente, bautiza a un hijo, bautiza a un ahijado y que es católico y eso no implica que salga del mundo en el que vive. Entonces, no es algo tan fatal. (Líder iglesia católica 1)

Hay personas que aún están en el tráfico, pero entran a la iglesia de a poco, porque eso es algo que va sucediendo gradualmente. [...] Ya no se ve esa gente tan atrapada en el mundo del tráfico. Dentro de un tiempo no estará más, como sucedió con otros. (Líder Asamblea de Dios)

Acerca de estas combinaciones, cabe mencionar el trabajo de Vital de la Cunha ${ }^{(30,32)}$ que exploró el caso de los "traficantes evangélicos" y problematizó la conversión como una supuesta ruptura con el mundo pasado del individuo. La autora, en su extenso estudio sobre una favela carioca, abordó "la amalgama entre religión, sociabilidad y criminalidad violenta"(32), reconstruyendo la historia de la asociación de los traficantes locales con la religión evangélica, a partir del proceso de conversión de uno de ellos, una persona de gran importancia en el contexto explorado. Ella relata cómo algunos individuos hacen "síntesis personales"(32) y concluyen que ellos mismos son las "fronteras entre el universo santo" $\mathrm{y}$ "el 'mundo del crimen'"(32).

A partir de la construcción discursiva de los entrevistados fue posible percibir que el abandono de las actividades criminales no se produce en todos del mismo modo: para algunos, se da en un continuo; para otros, de modo definitivo, lo que implica un cambio total de habitus. Un líder religioso narró el caso de una persona conocida que, aún estando involucrada con el tráfico, pasó a negarse a portar armas: "Él me dijo: 'Ya no me siento bien con esto entre las manos [armas], ¡va en contra de la vida!'" (líder iglesia católica 2). En el mismo sentido, un participante convertido, al reconstruir su experiencia personal, mencionó que el Evangelio habría actuado en su vida impidiéndole cometer actos violentos cuando aún estaba involucrado con el tráfico de drogas: "tenía miedo de practicar el mal porque ya tenía un poco de conocimiento del Evangelio" (M). Ambas historias evidencian diferencias en la forma de enfrentar la violencia a través de la evangelización. En algunos casos, la evangelización posibilitó una especie de "reducción de daños" en la medida en que, incluso siendo parte del tráfico de drogas, las personas evitaban actuar de forma violenta. Las formas de participación de las entidades religiosas para conseguir la conversión no están exentas de conflictos. Por un lado, se reafirma el carácter procesual de los cambios personales, los cuales implican recaídas. Por otro, algunos religiosos entrevistados criticaron duramente a las iglesias que permiten la presencia de traficantes y otras personas involucradas con el crimen. Estos críticos diferencian a las "personas que buscan de hecho modificar sus vidas" de las "personas que hacen un uso funcional de la religión", colocando en jaque la real disposición para el cambio. Prácticamente todos los sujetos de la investigación destacan la complejidad de las relaciones entre evangelización/conversión y violencia. O sea, hay un papel importante de "reducción de daños" en el proceso de conversión; sin embargo, hacerse creyente puede representar la posibilidad de abandonar la criminalidad y 
expresar un "cese de cuentas" con criminales y policías, que motiva a "esconderse detrás de la Biblia"(24,27). Por eso, al mismo tiempo que los agentes religiosos señalan la eficacia de la conversión, lanzan una mirada atenta y desconfiada, temiendo posibles deslices que evidencien la supuesta falacia en el cambio.

Mafra ${ }^{(50)}$ hace una reflexión importante respecto del papel de la comunidad en los procesos de conversión. Afirma que la categoría "conversión religiosa" individualiza un acontecimiento que forma parte de un proceso colectivo, en el contexto religioso. El quiebre instituido con relación a la vida anterior se refiere a un modo de ser socialmente visto como problemático por la comunidad. Así, la conversión nunca es solo del sujeto con relación a sí mismo, sino que forma parte de una creencia que envuelve a la comunidad, la que monitorea la conversión de acuerdo a criterios de moralidad. Del mismo modo, los participantes le atribuyeron una importancia significativa al grupo religioso que, por un lado, actúa a favor de los individuos que quieren cambiar de vida $y$, por otro, opera como control social.

Esta autora $^{(50)}$ realiza una distinción entre conversión máxima y conversión minimalista. En la primera, el individuo asume totalmente los preceptos de la denominación; en la segunda, se produce una especie de sincretismo individual, en el que las creencias antiguas pasan a convivir con las creencias del presente, en un proceso de asimilación o en una especie de "identidad híbrida" que acepta, al mismo tiempo, involucrarse con actos ilícitos y la participación religiosa. Ambas situaciones fueron encontradas en este estudio.

La "aceptación de Jesús" es considerada la cima de la conversión por las religiones protestantes, pero no la resume. Las trayectorias posibles son diversas, hacen que el individuo visualice que hay un conflicto entre el bien y el mal y que su pasaje de un lado al otro es posible. Esa acción implica que el individuo se objetive en el discurso religioso, e identifique, en primer lugar, el lado del mal y reconozca su cara criminal(29) para, luego, subjetivarse como convertido. Al convertirse, crea para sí una narrativa inversa: el mismo discurso anterior, pero resignificado. Teixeira ${ }^{(26)}$ analiza ese proceso en la construcción social del "ex bandido", y discute su complejidad y no linealidad, lo cual puede ser percibido también en los relatos de nuestros sujetos convertidos que destacaron las estrategias creadas para escapar de comportamientos como portar armas o actuar con violencia.

\section{La fuerza del liderazgo religioso}

En las iglesias, los pastores y los padres, entre otros líderes religiosos, ocupan un lugar privilegiado de saber-poder ${ }^{(51)}$, producen verdades sobre el modo correcto de vivir y dan concretitud a los sistemas de creencias que corroboran tales preceptos. El papel de los líderes religiosos es fundamental en la corporificación de la cosmología del grupo, al unir y garantizar que los individuos continúen en lo que consideran el camino verdadero. Hay una fuerza moral que les permite imponer autoridad en ciertas situaciones y salir inmunes en momentos de serios conflictos, como cuando interceden ante traficantes en acciones de rescate o evangelizan en los puntos de venta $^{(33)}$. Esa fuerza especial y el respeto se pudo vivenciar en varios momentos en el trabajo de campo, cuando los líderes religiosos eran interrumpidos constantemente por pedidos de bendiciones $y$, también, cuando eran requeridos en su espacio institucional.

Algunos de ellos viven en las mismas localidades en las que se encuentran sus iglesias, por lo que su cotidiano es más próximo a los miembros de las comunidades de fe, $y$ conocen de cerca las familias y sus necesidades materiales y espirituales. No hay como no ponderar el potencial impacto de tal proximidad en su visión sobre el lugar, su población y sus seguidores. Guimarães, Valla \& Lacerda ${ }^{(15)}$ destacan que la cercanía entre los religiosos y los habitantes de las comunidades propicia encuentros que, muchas veces, pueden provocar cambios radicales. Lessa subraya la fuerza de los líderes espirituales ante los problemas de salud en celebraciones colectivas: "el espacio de los cultos produce 
bienestar, fortalece la postura frente a las enfermedades y otras dificultades, y disminuye la angustia, además de traer cierto equilibrio a la salud mental y física"(12). Pastores y fieles ofrecen apoyo, mejoras y, cuando resulta necesario, auxilio material, en un sentido ya analizado por Minayo ${ }^{(4)}$ sobre la religiosidad popular.

Según Foucault ${ }^{(51)}$, discurso y práctica se entrecruzan. Lo que hace del habla un enunciado es su función enunciativa: la producción de un discurso, por un sujeto, en un espacio institucional legitimado por determinadas reglas históricas. Así, el discurso es una forma de poder y tiene valor de verdad dependiendo del saber-poder de quien lo prenuncia. Del discurso religioso de los líderes y de los convertidos emana la fuerza de la verdad respecto de la palabra de Jesús sobre el modo correcto de conducir la vida. En ese contexto, se constituye la identidad del creyente, subjetivándose en el discurso del líder religioso y reafirmándose en el grupo.

El lugar de poder ocupado por los líderes religiosos y expresado en sus relatos produce verdades sobre los individuos y es capaz de promover curas que, a veces, corresponden a la superación de enfermedades, pero también a cambios de comportamiento en dirección a una vida próspera o reconocida por la comunidad como moralmente correcta. El criminal que acepta a Jesús se torna un nuevo hombre creyente que, ahora, puede acceder a determinados bienes espirituales. Así, la palabra-discurso del agente religioso se une al deseo o a la necesidad de cambio del individuo que, dotado de una nueva identidad, se siente salvado y puede recomenzar.

Sin embargo, como ya fue mencionado, los sentidos atribuidos a los procesos que por momentos aproximan y por otros apartan a los sujetos de la fe y de la violencia son complejos y no van en una única dirección. Tales procesos pueden implicar un cambio radical de habitus o instituir procedimientos modulares que pueden o no ser clasificados como de conversión. Además, hay casos en los que el trabajo religioso -con relación al cual se genera una expectativa salvacionista- no produce contención y apoyo. Es el caso de la corrupción, reconocida como algo extremadamente grave dentro de las propias iglesias, por romper con el papel esperado de guía, y producir lo opuesto. Este punto fue realzado tanto por líderes católicos como protestantes.

Si trabajás con la fe tenés una responsabilidad muy grande con tu comportamiento ante aquel que estás asistiendo. Ahora, si él se topa con un comportamiento amoral nuestro, ahí se va todo a pique (líder iglesia católica 2).

Un participante convertido citó lo que denomina el "camino inverso" recorrido por religiosos que se desvían: "encontramos muchas personas en el tráfico que dicen, yo era pastor, yo fui pastor, yo fui diácono, yo fui presbítero" (R). Los líderes religiosos subrayan especialmente su preocupación, con una expresión denominada por ellos como "corrupción de las iglesias": la visión mercantilista de los que buscan lucro, que se alían a traficantes de drogas $y$ venden beneficios o aceptan dinero de grupos armados del territorio para realizar una serie de actividades, como fiestas. Los "bares de la fe", imagen evocada por un líder para describir ese fenómeno, se aprovechan de las necesidades de la población, ofreciendo "trabajos oportunistas" a cambio de dinero (líder iglesia católica 2), lo cual se le atribuye, sobre todo, a las iglesias evangélicas.

Hoy como iglesia, iglesia brasileña, iglesia evangélica, se escucha mucho que hay un crecimiento muy grande. [...] pero te voy a decir una cosa, hoy hay muchas personas usando el rótulo evangélico para su propio beneficio. Entonces conozco gente [que dice]: "voy a abrir una iglesia porque la iglesia atrae fieles" y fieles, cuando se habla fieles, ven cifras. Así, la iglesia brasileña está invirtiendo los valores, los conceptos del Reino de Dios. Ya lo vi. Por eso que tal vez nosotros no tengamos mucha credibilidad. Solo cuando la vida personal del líder tiene credibilidad, las personas creen en su trabajo. (Líder iglesia Batista) 
Cabe problematizar la intencionalidad de tales palabras. Periódicamente circulan noticias, en diversos medios de comunicación, que denuncian usos potencialmente espurios de iglesias, en especial de las evangélicas, que apuntan al lucro, lo que puede haber generado cierta preocupación, expresada en los discursos de los líderes, de desvincularse de tales prácticas consideradas corruptas.

Se entiende, pues, que las propias iglesias, a causa de sus líderes, pueden ser colocadas en jaque en cuanto a su poder de actuar en el territorio junto a la población. Delante del papel esperado y del peso de su discurso en la producción de sentidos sobre lo que es vivir una vida correcta, el comportamiento oportunista y corrupto puede desafiar la propia legitimidad de la institución y todo su trabajo religioso.

\section{ALGUNAS CONCLUSIONES}

El papel de las instituciones religiosas en el complejo de favelas objeto de este estudio es muy relevante, aunque sus sentidos varíen, sean complejos $y$, a veces, divergentes. La práctica religiosa puede representar una posibilidad de mejora de la calidad de vida, colaborar en la recuperación de personas enfermas y ofrecer la salvación a partir de la evangelización y de la conversión religiosa. Pero su presencia en barrios populares, como en este complejo, puede tener muchos otros significados e incluso colaborar con la reproducción de una visión estigmatizante sobre el territorio.

No se pretende homogeneizar el universo plural religioso brasileño, como tampoco la diversidad interna de las religiones evangélicas. Lo que se presenta aquí es el resultado de un estudio de caso concreto en un complejo de favelas, con las limitaciones propias de este tipo de estudios, respaldado por una amplia bibliografía nacional e internacional. En lo que respecta a los sentidos atribuidos al trabajo religioso, se encontraron más convergencias que divergencias entre los discursos de los participantes, como es el caso de la importancia de la evangelización en lugares de venta de drogas y de circulación de usuarios; de la inserción de los sujetos en comunidades de fe; de la perspectiva procesual y de la complejidad de la conversión a la religión; de la fuerza moral de los líderes; y de la contextualización del crimen como un "pecado social". Incluso, la preocupación por la corrupción de las iglesias aparece tanto en los discursos de los católicos como en el de los evangélicos.

Pero, también, se advierten diferencias, como es el caso de la conversión religiosa como culminación del proceso de recuperación, transformación y liberación citada, sobre todo, por los participantes de denominaciones evangélicas. Del mismo modo, puede considerarse como una limitación de este estudio el hecho de que solo los individuos evangélicos hayan narrado su proceso de conversión, dado que fueron ellos los que propusieron contar sus historias. Este aspecto, sin embargo, sugiere la importancia que las denominaciones pentecostales dan a la práctica del testimonio de sus fieles.

Otro punto importante destacado por el estudio son los diversos sentidos del término recuperación. Los testimonios de los entrevistados muestran que el impacto de la religión sobre la violencia no es de tipo "todo o nada", es decir, no es absoluto. Las transformaciones en la vida de los sujetos son reales; sin embargo, no siempre constituyen cambios radicales en el habitus. Incluso los sujetos se apropian de la conversión, considerada la culminación de la evangelización, de diversas formas: puede significar un cambio definitivo o solo de algunos aspectos que reducen los daños asociados a las prácticas ilegales y violentas. El abandono gradual de la participación en actos delictivos es posible, como un uso más funcionalista de la religión. Es el caso del traficante que "pide la bendición" al inicio de un día más de trabajo, como fue analizado por Vital de la Cunha ${ }^{(30)}$. Así, la religión institucionalizada puede servir como refugio, escudo o incluso excusa para prácticas ilegales.

Todos los líderes señalaron la fuerza de seducción ejercida por el poder de los grupos armados que dominan el territorio, dejando 
en claro que ellos mismos también pueden corromperse $y$, en mayor o menor grado, rendirse a esa seducción. Cuando la propia religión es cuestionada en su poder de salvación a causa de los desvíos de sus miembros, puede perder legitimidad en la comunidad y en el ejercicio del control social sobre la violencia. Los líderes que participaron en la investigación rechazaron tal hipótesis, tal vez queriendo asegurar la integridad de su trabajo.

A partir de los sentidos que los participantes otorgan al trabajo religioso y de las representaciones que construyen sobre el territorio, se concluye que el ethos peligroso, reforzado por el mito de la peligrosidad de las favelas -como nichos de criminalidad-, también refuerza la importancia de su propio trabajo, lo que aparece, sobre todo, en el relato de uno de los líderes evangélicos. O sea, en la práctica, hay una lógica según la cual las iglesias son necesarias porque se proponen cuidar un espacio social marginal. Ofrecen protección ante un cotidiano de vulnerabilidades y violencias en un territorio atravesado por el dominio de grupos armados; la falta de efectividad de las políticas públicas; la venta y consumo de drogas ilegales; el colapso del sistema de seguridad pública y la cultura de la violencia. A pesar de que los religiosos no consideren el pecado solo como un acto individual -pues definen la criminalidad como un "pecado social" - los procesos de recuperación y de salvación son atribuidos al individuo.

Los discursos críticos que apuntan a la violencia estructural y a una actuación compensatoria de las iglesias aparecen justamente entre los más comprometidos políticamente. Sin embargo, sus reflexiones no llegan a cuestionar el papel de la religión en el control social de los territorios peligrosos.

Sobre esa contradicción los líderes construyen su unidad y su fuerza; pues, el lugar de poder ocupado por los religiosos es legitimado exactamente por la capacidad que tienen de ordenar los espacios desorganizados y de producir subjetividades demarcadas por aquello que consideran el modo correcto de vivir, y que se corporifica en las narrativas de conversión. Afirmar que las acciones propuestas por las iglesias son, en gran parte, individuales y paliativas, no implica que no haya, entre los líderes, una visión más amplia de la realidad social en la que se insertan. El alcance de tales acciones, sin embargo, es restringido ante la complejidad de las situaciones enfrentadas en el cotidiano que dejan en claro las limitaciones de las iglesias como actores políticos capaces de producir transformaciones sociales. Su acción expresa, frecuentemente, la pacificación de la cuestión social. Estas contradicciones evocan la ausencia o la falta de efectividad de las acciones del poder público.

\section{AGRADECIMIENTO}

Al Conselho Nacional de Desenvolvimento Científico e Tecnológico, Edital MCT/CNPq No. 014/2010 Universal por la financiación (2010-2012) de la investigación "Visões e Estratégias sobre a Religião na Promoção, Prevenção e Recuperação de Pessoas Implicadas com a Violência", de la cual se desprende el presente trabajo.

\section{REFERENCIAS BIBLIOGRÁFICAS}

1. Ribeiro FML, Minayo MCS. The role of religion in the promotion of health, in the prevention of violence and in the rehabilitation of individuals involved in criminal activity: literature review. Ciencia \& Saude Coletiva. 2015;19(6):1773-1789.
2. Ribeiro FML, Minayo MCS. Religious therapeutic communities in recovering drug users: the case of Manguinhos, state of Rio de Janeiro, Brazil. Interface-Comunicação, Saúde, Educação. 2015;19(54):515-526.

3. Rabelo MC. Religião, ritual e cura. En: Alves PC, Minayo MCS, organizadores. Saúde e doença: um olhar antropológico. Rio de Janeiro: Fiocruz; 1994. p. 47-56.

4. Minayo MCS. Representações da cura no catolicismo popular. En: Alves PC, Minayo MCS, organizadores. Saúde e doença: um olhar antropológico. Rio de Janeiro: Fiocruz; 1994. p. 57-72.

5. Alves PC, Minayo MCS, organizadores. Saúde e doença: um olhar antropológico. Rio de Janeiro: Fiocruz; 1994. 
6. Mariz CL. Perspectivas sociológicas sobre o Pentecostalismo e o Neopentecostalismo. Revista de Cultura Teológica. 1995;(13):37-52.

7. Mariz CL. Embriagados no Espírito Santo: Reflexões sobre a experiência pentecostal e o alcoolismo. Antropolítica. 2003;(15):61-80.

8. Valla VV. O que a saúde tem a ver com a religião? En: Valla VV, organizador. Religião e cultura popular. Rio de Janeiro: DP\&A; 2001. p. 113-139.

9. Minayo MCS, Coimbra Júnior CEA, organizadores. Críticas e atuantes: ciências sociais e humanas em saúde na América Latina. Rio de Janeiro: Fiocruz; 2005.

10. Faria JB, Seidl EMF. Religiosidade e enfrentamento em contextos de saúde e doença: revisão da literatura. Psicologia: Reflexão e Crítica. 2005;18(3):381-389.

11. Panzini RG, Rocha NS, Bandeira DR, Fleck MPA. Qualidade de vida e espiritualidade. Revista de Psiquiatria Clínica. 2007;34(S1):105-115.

12. Lessa CF. A prática religiosa e a questão social: considerações sobre condições de vida e saúde na visão dos pastores e fiéis pertencentes à denominação metodista. [Dissertação de Mestrado]. Rio de Janeiro: Escola Nacional de Saúde Pública Sérgio Arouca; 2008.

13. Rocha MLA. O processo de recuperação do uso indevido de drogas em igrejas pentecostais Assembléia de Deus. [Dissertação de Mestrado]. Rio de Janeiro: Escola Nacional de Saúde Pública Sérgio Arouca; 2010.

14. Novaes RR. Pentecostalismo, política, mídia e favela. En: Valla VV, organizador. Religião e cultura popular. Rio de Janeiro: DP\&A; 2001. p. 41-74.

15. Guimarães MBL, Valla VV, Lacerda A. As redes de apoio social constituídas por pastores e agentes comunitários de saúde evangélicos no âmbito do cuidado e atenção à saúde da população. Religião e Saúde [Internet]. 2009 [citado 8 ago 2015]. Disponible en: https://goo.gl/AXjJa7.

16. Fernandes SRA. Marcos definidores da condição juvenil para católicos e pentecostais. Religião \& Sociedade. 2011;31(1):96-125.

17. Ribeiro C, Lopes $\mathrm{N}$, organizadores. Vinte anos depois: a vida e a missão da igreja em foco. São Bernardo do Campo: Editeo; 2002.

18. Ribeiro $C$, Cunha $M$. O rosto ecumênico de Deus: reflexões sobre ecumenismo e paz. 18a ed. São Paulo: Fonte Editorial; 2013.
19. Dalgalarrondo P. Relações entre duas dimensões fundamentais da vida: saúde mental e religião. Revista Brasileira de Psiquiatria. 2006;28(3):177-178.

20. Stroppa A, Moreira-Almeida A. Religiosidade e Saúde. En: Salgado MI, Freire G, organizadores. Saúde e espiritualidade: uma nova visão da medicina. Belo Horizonte: Inede; 2008. p. 427-443.

21. Vargas LO. Religiosidade: mecanismo de sobrevivência na penitenciária feminina do Distrito Federal. Comunicações do ISER. 2005;24(61):30-39.

22. Segato RL. Religião, vida carcerária e direitos humanos. Comunicações do ISER 2005;(61):40-46.

23. Scheliga EL. Trajetórias religiosas e experiências prisionais: a conversão em uma instituição penal. Comunicações do ISER 2005;24(61):75-85.

24. Scheliga EL. Sob a proteção da Bíblia? A conversão ao pentecostalismo em unidades penais paranaenses. Debates do NER. 2005;6(8):57-71.

25. Rodrigues GE. Transgressão, controle social e religião: um estudo antropológico sobre práticas religiosas na penitenciária feminina do estado do Rio Grande do Sul. Debates do NER. 2005;6(8):9-20.

26. Quiroga AM. Religiões e prisões no Rio de Janeiro: presença e significados. Comunicações do ISER. 2005;24(61):13-21.

27. Dias CCN. Evangélicos no cárcere: representações de um papel desacreditado. Debates do NER. 2005;6(8):39-55.

28. Lobo ES. Católicos e evangélicos em prisões do Rio de Janeiro. Comunicações do ISER 2005;24(61):22-29.

29. Teixeira CP. A construção social do "exbandido": um estudo sobre sujeição criminal e pentecostalismo. [Dissertação de Mestrado]. Rio de Janeiro: Universidade Federal do Rio de Janeiro; 2009.

30. Cunha CV. Evangélicos em ação nas favelas cariocas: um estudo sócio-antropológico sobre redes de proteção, tráfico de drogas e religião no Complexo de Acari. [Dissertação de doutorado]. Rio de Janeiro: Universidade do Estado do Rio de Janeiro; 2009.

31. Minayo MCS. Saúde-doença: uma concepção popular da etiologia. Cadernos de Saúde Pública. 1988;4(4):363-381.

32. Cunha CV. Religião e criminalidade: traficantes e evangélicos entre os anos 1980 e 2000 nas favelas cariocas. Religião e Sociedade. 2014;34(1):61-93. 
33. Natividade M, Oliveira L. Sexualidades ameaçadoras: religião e homofobia(s) em discursos evangélicos conservadores. Sexualidad, Salud y Sociedad-Revista Latinoamericana. 2009;(2):121-161.

34. Campos LS. Evangélicos, pentecostais e carismáticos na mídia radiofônica e televisiva. Revista USP. 2004;(61):146-163.

35. Silva RC. Conflitos religiosos e espaço urbano contemporâneo: cruzamento dos fenômenos de dispersão espacial dos sistemas de significações religiosas de neopentecostais e religiões afrobrasileiras no Rio de Janeiro. [Dissertação de Mestrado]. Santa Maria: Universidade Federal de Santa Maria, Centro de Ciências Naturais e Exatas; 2013.

36. Bohn SR. Evangélicos no Brasil: perfil socioeconômico, afinidades ideológicas e determinantes do comportamento eleitora. Opinião Pública. 2004;10(2):288-338.

37. Bodstein RCA, Zancan L. Avaliação das ações de promoção da saúde em contextos de pobreza e vulnerabilidade social. En: Zancan L, Bodstein RCA, Marcondes WB, organizadores. Promoção da saúde como caminho para o desenvolvimento local: a experiência em Manguinhos-RJ. Rio de Janeiro: ABRASCO; 2002. p. 39-59.

38. Perlman JE. O mito da marginalidade. Rio de Janeiro: Paz Terra; 1977.

39. Silva LAM. Introdução. En: Silva LAM, organizador. Vida sob cerco-violência e rotina nas favelas do Rio de Janeiro. Rio de Janeiro: Nova Fronteira; 2008. p. 13-26.

40. Escola Nacional de Saúde Pública Sergio Arouca, Fundação Oswaldo Cruz. Participação Cidadã na Gestão da Saúde de Manguinhos [Internet]. Fiocruz, Escola Nacional de Saúde Pública Sergio Arouca; 2011 [citado 14 ago 2012]. Disponible en: https://tinyurl.com/y8new4as.

41. Bodstein RCA, Magalhães R, Marcondes WB, organizadores; Coelho AVAG, colaboradora. Equipamentos e iniciativas sociais em Manguinhos. Rio de Janeiro: Ediouro; 2011.
42. Cardoso ALC, Pivetta F, Porto MFS, Cunha MB, coordinadores. Relatório; PAC Manguinhos: problemas não resolvidos e recomendações [Internet]. Rio de Janeiro: Laboratório Territorial de Manguinhos, Arquitetando Intersubjetividades, LSECAU, FIOCRUZ, ENSP; 2016 [citado 24 jun 2017]. Disponible en: https://tinyurl.com/y8xk4mmb.

43. Minayo MCS. Desafio do conhecimento: pesquisa qualitativa em saúde. 11a ed. São Paulo: Hucitec; 2008.

44. Silva JS, Fernandes FL, Braga RW. Grupos criminosos armados com domínio de território: reflexões sobre a territorialidade do crime na Região Metropolitana do Rio de Janeiro. En: Justiça Global, organizadora. Segurança, Tráfico e Milícia no Rio de Janeiro. Rio de Janeiro: Fundação Heinrich Böil; 2008. p. 16-24.

45. Das V, Poole D. State and its margins. En: Das V, Poole D, editors. Anthropology in the Margins of the State. Oxford: James Currey; 2004. p. 3-33.

46. Minayo MCS, Constantino P. Visão ecossistêmica do homicídio. Ciência \& Saúde Coletiva. 2012;17(12):3269-3278.

47. Geertz C. A religião como sistema cultural. En: Geertz C. A interpretação das Culturas. Rio de Janeiro: LTC; 2008.

48. Bourdieu P. A economia das trocas simbólicas. São Paulo: Perspectiva; 2007.

49. Teixeira CP. O testemunho e a producão de valor moral: observações etnográficas sobre um centro de recuperação evangélico. Religião \& Sociedade. 2016;36(2):107-134.

50. Mafra C. Relatos compartilhados: experiências de conversão ao pentecostalismo entre brasileiros e portugueses. Mana. 2000;6(1):57-86.

51. Foucault M. Arqueologia do saber. Rio de Janeiro: Forense Universitária; 1986.

\section{FORMA DE CITAR}

Ribeiro FML, Minayo MCS. Sentidos del trabajo religioso en contextos marcados por la violencia: estudio en un complejo de favelas en Río de Janeiro. Salud Colectiva. 2018;14(2):273-288. doi: 10.18294/sc.2018.1492.

Recibido: 29 de junio de 2017 | Versión final: 9 de febrero de 2018 | Aprobado: 19 de febrero de 2018 